\title{
Prevalence of Escherichia coli 0157 and Levels of Aerobic Bacteria and Enterobacteriaceae Are Reduced When Hides Are Washed and Treated with Cetylpyridinium Chloride at a Commercial Beef Processing Plant ${ }^{\dagger}$
}

\author{
JOSEPH M. BOSILEVAC, ${ }^{1 *}$ TERRANCE M. ARTHUR, ${ }^{1}$ TOMMY L. WHEELER, ${ }^{1}$ STEVEN D. SHACKELFORD, ${ }^{1}$ \\ MICHELLE ROSSMAN, ${ }^{2}$ JAMES O. REAGAN, ${ }^{2}$ AND MOHAMMAD KOOHMARAIE ${ }^{1}$
}

\begin{abstract}
${ }^{1}$ U.S. Department of Agriculture, Agricultural Research Service, Roman L. Hruska U.S. Meat Animal Research Center, Clay Center, Nebraska 68933-0166; and ${ }^{2}$ National Cattlemen's Beef Association, 9110 East Nichols Avenue, Centennial, Colorado 80112, USA
\end{abstract}

MS 03-264: Received 13 June 2003/Accepted 29 October 2003

\begin{abstract}
The objective of this experiment was to test the potential of a combined water wash and cetylpyridinium chloride (CPC) treatment as a hide intervention applied to cattle in the holding pens of a processing plant immediately before stunning. Over 2 processing days, 149 control and 139 treated cattle were tested. Control cattle were processed in the normal manner. The treatment group was prewashed with water the day before harvest. Immediately before stunning, these cattle were sprayed twice with $1 \% \mathrm{CPC}$, first for $3 \mathrm{~min}$, then for $1 \mathrm{~min}$. Hides and preevisceration carcasses were sampled to determine aerobic plate counts, Enterobacteriaceae counts (EBC), and Escherichia coli $\mathrm{O} 157$ prevalence. The treatment reduced the prevalence of $E$. coli $\mathrm{O} 157$ on hides from $56 \%$ to $34 \%$ and the prevalence on preevisceration carcasses from $23 \%$ to $3 \%$. The treatment decreased aerobic plate counts from $4.9 \log$ CFU/100 cm to $3.4 \log$ CFU/100 $\mathrm{cm}^{2}$ and EBC from $3.1 \log \mathrm{CFU} / 100 \mathrm{~cm}^{2}$ to $2.0 \log \mathrm{CFU} / 100 \mathrm{~cm}^{2}$ on preevisceration carcasses. The treatment of hides did not result in any detectable CPC contamination of the chilled carcasses. These data indicated that a $1 \%$ CPC treatment preceded by a water wash was capable of reducing hide prevalence of $E$. coli $\mathrm{O} 157$ from as high as $80 \%$ to less than $50 \%$, resulting in preevisceration carcass prevalence of 5\% or less. We conclude that water washing followed by an antimicrobial treatment, such as CPC, has great potential as an effective hide intervention step and should be further evaluated for implementation as a processing step after stunning and before hide removal.
\end{abstract}

Beef carcass contamination by pathogens such as Escherichia coli $\mathrm{O} 157: \mathrm{H} 7$ and Salmonella has been shown to occur principally from hides during the removal process ( 3 , $4,9)$. Although there are numerous carcass interventions in beef processing plants $(2,10,16)$, occasional contamination events occur that these interventions cannot completely remove. Nou et al. (13) recently demonstrated that the most efficient means to eliminate carcass contamination is to prevent it in the first place by cleaning the hide before its removal. Their study evaluated chemical dehairing as the hide intervention and showed that it virtually eliminated carcass contamination with E. coli O157:H7. They also suggested that cetylpyridinium chloride (CPC) application, if effective, may be more feasible than chemical dehairing as a hide intervention.

CPC is a common oral antimicrobial (14) and has been described by Slavik and coworkers $(11,18,19)$ for use in decontamination of chicken carcasses in the poultry indus-

\footnotetext{
* Author for correspondence. Tel: 402-762-4225; Fax: 402-762-4149 E-mail: bosilevac@email.marc.usda.gov.

$\dagger$ Names are necessary to report factually on available data; however, the U.S. Department of Agriculture neither guarantees nor warrants the standard of the product, and the use of the name by the U.S. Department of Agriculture implies no approval of the product to the exclusion of others that may also be suitable.
}

try. Experiments that applied CPC to beef have focused on the decontamination of carcasses (8) and trim before grinding (15) rather than the decontamination of hides prior to removal. We recently reported on a series of experiments designed to determine the optimal application of CPC as a hide intervention (6). Those results indicated that, under the proper conditions, CPC treatment can be effective for reducing microbial populations on cattle hides. Additionally, the results established the parameters needed to develop a protocol to test whether a $1 \%$ CPC hide intervention process would reduce microbial contamination of the carcass by bacteria from the hide during processing (6).

We assume that the most feasible application of CPC as a cattle hide intervention would be on the stunned, shackled animal in the processing plant. However, CPC is not approved for use in a beef processing plant, so further validation of its application required testing under conditions that mimic, as closely as possible, the conditions of in-plant application, while actually applying the CPC intervention to live animals outside the processing plant. Thus, the objective of this experiment was to further test the potential of CPC as a hide intervention by applying the treatment to cattle in the holding pens of the processing plant immediately before stunning. When processed in this manner, we observed reduced hide and preevisceration carcass 
contamination in the $\mathrm{CPC}$-treatment group. Preevisceration carcass aerobic plate counts (APC) and Enterobacteriaceae counts (EBC) were reduced in the CPC treatment group, and the prevalence of $E$. coli $\mathrm{O} 157$ on hides was significantly reduced, correlating with near elimination of the pathogen from preevisceration carcasses.

\section{MATERIALS AND METHODS}

Experimental design. On 2 consecutive days, 150 cattle were randomly selected from a feedlot pen (a different pen each day). Cattle from each pen were randomly divided into two groups of 75. Cattle from one group were conventionally processed and sampled as controls. The other 75 were prewashed with potable water the day before slaughter to remove as much visible contamination as possible from the hide, then kept overnight in a clean holding pen at the processing plant. The control cattle were the first cattle processed at the beginning of the shift the next day. As was standard protocol for this plant, the control cattle were wetted with water as they proceeded up the alley to the stunning chute. CPC-treated cattle were treated and processed in three groups spaced throughout the day. Hides and preevisceration carcasses were sampled for APC, EBC, and E. coli O157 detection.

CPC treatment. Cattle were treated with CPC in three groups, ranging in size from 14 to 30 head. Each animal was held in a squeeze chute with head restrained during treatment. Potable water was used with an electric power pressurized sprayer (Karcher, Duluth, Ga.) possessing a rotating nozzle to dispense $1 \%$ CPC (Safe Foods Corp., North Little Rock, Ark.) from 40\% stock. Hides were sprayed at a setting of $500 \mathrm{lb} \mathrm{in}^{-2}$ and the distance from nozzle to hide was kept at approximately $65 \mathrm{~cm}$. Each animal received a $3-\mathrm{min}$ spray of $1 \% \mathrm{CPC}$. The spray covered the entire animal, except for the head, and focused especially on the areas associated with the hide opening pattern line along the brisket, belly, crotch, perianal, and hock. The first wash was designed to clean the hide as much as possible. After the first CPC wash was completed for a group, that group was sent through the chute for a second CPC wash. The second CPC wash was $1 \mathrm{~min}$ and was intended to resoak the hide with CPC immediately before stunning. Treated cattle were not water washed in the alley leading to the stunning chute. On day 1 , there were 64 treated cattle and 75 control cattle. On day 2 , there were 75 treated cattle and 74 control cattle.

CPC concentration. The concentration of CPC was confirmed before and while spraying each treatment group by measuring the optical density at a wavelength of $260 \mathrm{~nm}$ with a spectrophotometer Samples of diluted CPC $(50 \mathrm{ml})$ were collected from the sprayer nozzle and diluted 1:100 in warm $\left(37^{\circ} \mathrm{C}\right)$ distilled water. The absorbance at $260 \mathrm{~nm}$ of the 1:100 dilution was linear in the range of 0.100 to 1.500 and a $1 \%$ solution of CPC gave an absorbance of approximately 1.000. Optical density measurements at a wavelength of $260 \mathrm{~nm}$ with values between 0.850 and 1.150 were used to establish the concentration of CPC.

Sampling of hides and carcasses. All hide samples were collected using Speci-Sponge bags (Nasco, Fort Atkinson, Wis.) containing $25 \mathrm{ml}$ Dey-Engley neutralization broth (Difco, Detroit, Mich.) prepared at $2 \times$ concentration (78 g/liter). Hide samples were taken from $500 \mathrm{~cm}^{2}$ of the plate-brisket area using 10 bidirectional strokes of the sponge, turned over halfway through the process. Preevisceration carcass samples were collected using Speci-Sponge bags containing $25 \mathrm{ml}$ buffered peptone water (Difco). Samples were collected from an $8,000-\mathrm{cm}^{2}$ area that covered the inside and outside round of the left and right sides of each carcass.

APC and EBC. The contents of all preevisceration carcass sample bags were thoroughly mixed by hand massaging that consisted of firmly squeezing the sample bag and sponge a minimum of five repetitions or until a uniform suspension was visible in the bag. Aliquots $(1.5 \mathrm{ml})$ were taken directly from the bags for 10fold serial dilutions in buffered peptone water. One milliliter of each subsequent serial dilution was plated to $3 \mathrm{M}$ Microbiology (St. Paul, Minn.) Aerobic Count Plate (AC) Petrifilm and Enterobacteriaceae (EB) Petrifilm. AC Petrifilm was incubated 36 to $40 \mathrm{~h}$ at $35^{\circ} \mathrm{C}$ and EB Petrifilm was incubated 16 to $20 \mathrm{~h}$ at $37^{\circ} \mathrm{C}$ before enumeration by manual counting.

E. coli 0157 detection. Detection of E. coli $\mathrm{O} 157$ consisted of enrichment, immunomagnetic separation, and plating as described previously (5) with minor modifications. All sample bags were enriched by the addition of $75 \mathrm{ml}$ tryptic soy broth (Difco) immediately after the aliquot for centrifugation was collected. Once all sample bags received tryptic soy broth, they were placed as a group into a programmable incubator for enrichment. The program for enrichment was $2 \mathrm{~h}$ at $25^{\circ} \mathrm{C}, 6 \mathrm{~h}$ at $42^{\circ} \mathrm{C}$, and 6 to $10 \mathrm{~h}$ at $5^{\circ} \mathrm{C}$. One milliliter of enriched culture was used in immunomagnetic separation with anti-E. coli O157 DynaBeads (Dynal, Lake Success, N.Y.) following the manufacturer's instructions. Bacterial cells bound to the beads were plated on sorbitol MacConkey (Difco) plates supplemented with $0.05 \mathrm{mg} /$ liter of cefixime and $2.5 \mathrm{mg} / \mathrm{liter}$ of potassium tellurite (Dynal) (ctSMAC), and Rainbow Agar (Biolog, Hayward, Calif.) plates supplemented with $10 \mathrm{mg} /$ liter of novobiocin (Sigma) and $8 \mathrm{mg} /$ liter of potassium tellurite (Sigma) (ntRainbow). The plates were incubated at $37^{\circ} \mathrm{C}$ for $16 \mathrm{~h}$ and suspect colonies were confirmed to be $E$. coli O157 using Oxoid (Ogdensburg, N.Y.) DrySpot latex agglutination tests. The suspect colonies that tested positive with latex agglutination were considered to be $E$. coli $\mathrm{O} 157: \mathrm{H} 7$, as greater than $90 \%$ of similar isolates had been confirmed to be E. coli O157: $\mathrm{H} 7$ in earlier studies (3), but are referred to herein as E. coli $\mathrm{O} 157$ to avoid misinterpretation of the level of organism identification.

Within each group of samples (hide/carcass, treated/control), an additional sample was processed as an immunomagnetic separation control. A green fluorescent protein-expressing strain of E. coli $\mathrm{O} 157: \mathrm{H} 7$ was added to hide positive control samples at $200 \mathrm{CFU}$ per sample, and to carcass positive control samples at $20 \mathrm{CFU}$ per sample before enrichment. Following enrichment, immunomagnetic separation, and plating, the ctSMAC plates were viewed under an ultraviolet lamp to confirm the presence of green fluorescent protein-positive colonies.

Residual CPC on carcasses. Surface samples of subcutaneous adipose tissue were collected from the exterior of each carcass belonging to a CPC-treated animal after it entered the chill cooler. Samples (approximately $400 \mathrm{~g}$ each) were assayed for CPC using the high-performance liquid chromatography method previously described (8).

Carcass quality. Carcass quality grades and dark-cutting scores and downgrades were obtained by the U.S. Department of Agriculture on-line grader (1). Bruising data were obtained by processing plant quality-assurance personnel.

Statistical analysis. Data were analyzed by analysis of variance using the GLM procedures of SAS (SAS Inst. Inc., Cary, N.C.) for a 2 (treatment) $\times 2$ (day) factorial arrangement of a completely randomized design. The model included the main effects of treatment (control or CPC-treated) and day (day 1 or day 
TABLE 1. Main effect and interaction between days of cetylpyridinium chloride $(C P C)$ hide intervention on carcass $^{a} A P C^{b}$ and $E B C^{c}$

\begin{tabular}{llll}
\hline Treatment & $n$ & APC & EBC \\
\hline Main effect & & & \\
Control & 149 & 4.9 & 3.1 \\
Treated & 139 & 3.4 & 2.0 \\
SEM & & 0.04 & 0.05 \\
$P$ value & & 0.0001 & 0.0001 \\
Interaction & & & \\
Day 1 & & & \\
Control & 75 & $4.5 \mathrm{~B}^{d}$ & $2.8 \mathrm{~B}$ \\
Treated & 64 & $3.4 \mathrm{C}$ & $2.0 \mathrm{C}$ \\
Day 2 & & & \\
Control & 74 & $5.3 \mathrm{~A}$ & $3.3 \mathrm{~A}$ \\
Treated & 75 & $3.3 \mathrm{C}$ & $2.0 \mathrm{C}$ \\
SEM & & 0.04 & 0.05 \\
$P$ value & & 0.0001 & 0.0005 \\
\hline
\end{tabular}

${ }^{a}$ Carcass samples were collected preevisceration, before any interventions, from an area of $8,000 \mathrm{~cm}^{2}$ and values are presented as mean of $\log \mathrm{CFU} / 100 \mathrm{~cm}^{2}$.

${ }^{b}$ Aerobic plate counts.

${ }^{c}$ Enterobacteriaceae counts.

${ }^{d}$ Means of interaction within a column with a common letter are not different $(P>0.05)$.

2). Pairwise comparisons of frequencies were made using PROC FREQ and Mantel-Haenszel chi-square analysis of SAS.

\section{RESULTS AND DISCUSSION}

APC and EBC. Immediately following the removal of hides from treated and control cattle, the preevisceration carcass levels of APC and EBC were measured as general indicators of cleanliness (Table 1). Carcasses from treated cattle had $1.5 \log \mathrm{CFU} / 100 \mathrm{~cm}^{2}$ lower APC levels and 1.0 $\log$ CFU/100 $\mathrm{cm}^{2}$ lower EBC levels compared with carcasses from control cattle. This effect was similar for both days. The treatment $\times$ day interaction was not significant for APC or EBC $(P>0.05)$ but counts on control carcasses were slightly higher on day 2 than on day 1 . Nevertheless, the APC and EBC levels were significantly decreased $(P$ $<0.05)$ in the treatment groups on both days. Our results indicate that treatment with CPC significantly reduces hideto-carcass transfer of contaminants and enhances the overall carcass cleanliness as measured by APC and EBC.

We used EB and AC Petrifilm to measure EBC and APC levels. Chemically injured cells are generally not resuscitated on selective media such as the EB Petrifilm. Therefore, the EBC levels measured on treated carcasses could possibly have been greater. However, the log reductions we observed following CPC treatment suggest that, even if we had been able to measure additional putative injured bacteria, the impact on results would have been insignificant.

The activity of CPC on hides has been shown to be effective as soon as $30 \mathrm{~s}$ and as long as $4 \mathrm{~h}$ after application (6). This compares with other descriptions of CPC activity
TABLE 2. Main effect and interaction between days of cetylpyridinium chloride $(C P C)$ treatment on prevalence of E. coli $O 157$ on hides and carcasses ${ }^{a}$

\begin{tabular}{|c|c|c|c|}
\hline Treatment & $n$ & Hide $^{b}$ & Carcass $^{c}$ \\
\hline \multicolumn{4}{|l|}{ Main effect } \\
\hline Control & 149 & $56 \mathrm{~A}^{d}$ & $23 \mathrm{~A}$ \\
\hline Treated & 139 & 34 в & 3 в \\
\hline \multicolumn{4}{|l|}{ Interaction } \\
\hline \multicolumn{4}{|l|}{ Day 1} \\
\hline Control & 75 & $81 \mathrm{~A}$ & $42 \mathrm{~A}$ \\
\hline Treated & 64 & 42 в & 0 в \\
\hline \multicolumn{4}{|l|}{ Day 2} \\
\hline Control & 64 & 31 в & 3 в \\
\hline Treated & 75 & 27 в & 5 в \\
\hline \multicolumn{4}{|c|}{$\begin{array}{l}{ }^{a} \text { Results given as percentage positive for } E \text {. coli } \mathrm{O} 157 \text { by culture } \\
\text { identification. }\end{array}$} \\
\hline \multicolumn{4}{|c|}{$\begin{array}{l}{ }^{b} \text { Hides were sampled after stunning from an area of } 500 \mathrm{~cm}^{2} \text {. } \\
{ }^{c} \text { Preevisceration carcasses were sampled from the left and right } \\
\text { inside and outside round, for a total area of } 8,000 \mathrm{~cm}^{2} .\end{array}$} \\
\hline
\end{tabular}

dwell times that ranged from $3 \mathrm{~min}$ on poultry carcasses (11) to days and weeks on beef carcasses and in vacuumpacked products $(8,15)$. The cattle treated in this study were processed such that the hides were removed within 30 min of the final CPC treatment. A $1 \%$ solution of CPC was applied to the hides of the cattle in our study. Effective CPC concentrations on produce and poultry carcasses have been reported as $0.1 \%$ and $0.5 \%(11,18,19)$. On beef products, Pohlman et al. (15) treated beef trim with $0.5 \% \mathrm{CPC}$ and Cutter et al. (8) treated beef surfaces with $1 \%$ CPC. For hides, it was shown that a CPC concentration of $1 \%$ was sufficient for activity and that using concentrations above $1 \%$ presented additional sample processing problems, whereas concentrations less than $1 \%$ did not provide sufficient decontamination (6).

Prevalence of $\boldsymbol{E}$. coli $\mathbf{O 1 5 7}$. The prevalence of $E$. coli O157 was determined for all hides and preevisceration carcasses in our study (Table 2). CPC treatment reduced $(P<$ $0.05)$ the prevalence of $E$. coli $\mathrm{O} 157$ on hides. However, the treatment $\times$ day interaction was significant $(P<0.05)$ for hides. On day 1, controls had higher prevalence of $E$. coli $\mathrm{O} 157$ on hides than did controls on day 2. Thus, the treatment effect was much greater on day 1 than on day 2 . The day-to-day variation in microbial status of the cattle hides may have been due to the inactivation of CPC by organic matter on the hides or natural pen-to-pen variation in prevalence of E. coli $\mathrm{O} 157$. We speculate that the day 2 group of cattle presented with dirtier hides than the day 1 group. Despite our efforts to remove as much visible contamination as possible with the water wash, there may still have been significant levels of organic matter present. Quaternary ammonium compounds such as CPC are rapidly inactivated by organic matter (12). Therefore, the activity of the CPC on day 2 cattle could have been diminished 
relative to day 1 cattle and resulted in a decreased reduction of $E$. coli $\mathrm{O} 157$ hide prevalence compared with day 1. Alternately, E. coli $\mathrm{O} 157$ hide prevalence was lower on the day 2 control cattle. Wide pen-to-pen variations in $E$. coli O157 prevalence have been reported. Smith et al. (17) have observed that the prevalence of cattle shedding $E$. coli O157:H7 can vary greatly between pens at the same feedyard. They noted pens within five different feedyards where shedding prevalence ranged from $5 \%$ or less up to 40 to $80 \%$. The relationship between the shedding of $E$. coli O157 and its prevalence on hides has not been addressed, but the relationship could be assumed to be a positive one in which a small number of shedders contaminate a small portion of their pen mates while a large number of shedders can contaminate a large portion of their pen mates.

The transfer of E. coli O157 to the carcass following hide removal was reduced when hides had been treated with CPC (Table 2). The overall prevalence of E. coli 0157 on control preevisceration carcasses was $23 \%$ and was reduced to $3 \%$ on preevisceration carcasses from the CPC-treated cattle. However, the treatment $\times$ day interaction for $E$. coli O157 prevalence on preevisceration carcasses was significant $(P<0.05)$. The CPC treatment effect on $E$. coli $\mathrm{O} 157$ prevalence on preevisceration carcasses was greater $(P<$ 0.05 ) on day 1 than on day 2 . This interaction occurred because E. coli 0157 prevalence on preevisceration carcasses on day 2 was too low to allow for a large treatment effect. A similar correlation in the prevalence of $E$. coli O157 on hides and preevisceration carcasses was noted by Nou et al. (13), who observed that a low prevalence of $E$. coli $\mathrm{O} 157$ on hides correlated to lower prevalence on carcasses, and a higher prevalence of E. coli $\mathrm{O} 157$ on hides correlated to increased prevalence on carcasses. It was not unexpected then that our day 2 data were so low because the hide prevalence that day was $60 \%$ less than that of day 1. Our data also indicate that CPC treatment preceded by a water wash that is applied in a manner that mimics how it might be applied in a wash cabinet in a processing plant after stunning is capable of reducing hide prevalence of $E$. coli from as high as $80 \%$ to less than $50 \%$, resulting in preevisceration carcass prevalence of $5 \%$ or less. If preevisceration carcass prevalence can be reduced to this low level by a hide intervention, then pathogens subsequently can be eliminated or virtually eliminated from the carcass by interventions applied during dressing procedures.

CPC on carcasses. CPC was not detected on any subcutaneous (outside) fat samples from the 139 dressed, chilled carcasses of the CPC-treated cattle (data not shown). This implied that CPC could be used safely on hides with low concern for transfer to final product. Despite the fact that CPC is a commonly used oral antimicrobial, it has been determined that the allowable limit for an average adult (70 $\mathrm{kg}$ body weight) would be $4.4 \mathrm{mg} /$ day (8). Therefore, the $1 \%$ level we used on hides could theoretically cause an unacceptable level of exposure to CPC if significant amounts were transferred to the carcass either through penetration of the hide or during hide removal. The CPC was presumably removed with the hide, and any CPC trans-
TABLE 3. Effects of cetylpyridinium chloride $(C P C)$ application process on carcass quality ${ }^{a}$

\begin{tabular}{lcc}
\hline \multicolumn{1}{c}{ Grade $^{b}$} & Control $(n=74)$ & CPC treated $(n=75)$ \\
\hline Standard & $7 \mathrm{~A}^{c}$ & $18 \mathrm{~B}^{d}$ \\
Select & $44 \mathrm{~A}^{e}$ & $47 \mathrm{~A}$ \\
Choice & $47 \mathrm{~A}^{f}$ & $35 \mathrm{~B}$ \\
Prime & $3 \mathrm{~A}$ & $0 \mathrm{~A}$ \\
Bruised & $0 \mathrm{~A}$ & $7 \mathrm{~B}$ \\
Dark & $4 \mathrm{~A}$ & $10 \mathrm{~A}$ \\
Downgraded & $3 \mathrm{~A}$ & $10 \mathrm{~A}$ \\
\hline
\end{tabular}

$a$ Values represent percentage in each grade of carcasses from each treatment group. Data were gathered from processing plant quality-assurance personnel and U.S. Department of Agriculture online grader.

${ }^{b}$ Grades and comments affecting grade.

${ }^{c}$ Values within a grade with a common letter are not different $(P$ $>0.05$ ).

${ }^{d}$ Seven dark-cutting carcasses downgraded from select to standard.

${ }^{e}$ One dark-cutting carcass downgraded from choice to select.

$f$ One dark-cutting carcass downgraded from prime to choice.

ferred to the carcass during hide removal was washed away during subsequent interventions.

Carcass grade data. Because the CPC application had to be simulated on live cattle rather than applied after stunning, an increased level of stress and bruising was introduced in the treated cattle. This resulted from prewashing the cattle the day before harvest, putting them through a chute twice, and spraying them with CPC for 3 and $1 \mathrm{~min}$, respectively, immediately before stunning. Therefore, the incidence of carcass bruising was increased and more darkcutting quality grade discounts were applied to the treated group compared with controls (Table 3). The incidence of dark-cutting (dark red lean color in the ribeye muscle rather than bright cherry red) doubled. Compared with control carcasses, a greater percentage of carcasses from CPC-treated cattle had lean color dark enough to require down-grading to the next lower quality grade, which reduced the value of the carcasses. The percentage of bruised carcasses that required trimming was greater for $\mathrm{CPC}$ treatment than for controls. These data provide further evidence that hide interventions should be applied after, rather than immediately before, stunning.

The data presented demonstrate that, when it is properly applied after a water wash, CPC treatment can be used as an effective hide intervention step to reduce or eliminate the incidence of pathogens, such as E. coli $\mathrm{O} 157: \mathrm{H7}$, from preevisceration carcasses. The data presented here show that pressurized application of $1 \% \mathrm{CPC}$ to prewashed cattle can achieve reductions in prevalence of E. coli $\mathrm{O} 157$ on hides from $81 \%$ to $42 \%$, and this reduction translated to a reduction of incidence on preevisceration carcasses from $42 \%$ to $0 \%$. The use of the water wash alone and the CPC treatment alone were not examined in these studies. We have previously noted (6) that pressure washing of pulled hides to remove all visible contaminants only resulted in a 
$50 \%$ reduction in bacterial load when measured by APC or EBC. Other reports have stated that water washing of hides for $1 \mathrm{~min}$ did not alter subsequent carcass contamination rates (7). The function of the water wash in our study was to remove interfering organic matter prior to the CPC treatment. As mentioned above, CPC can be rapidly inactivated by organic matter (12); this was observed in our earlier studies (6) using live feedlot cattle. Therefore, based on our previous report, a water wash was designed to be an integral part of our CPC hide intervention protocol. We conclude that an antimicrobial treatment, such as CPC, has great potential as an effective hide intervention step and should be further evaluated for implementation as a processing step after stunning and before hide removal.

\section{ACKNOWLEDGMENTS}

This project was funded in part by beef and veal producers and importers through their $\$ 1$-per-head check off and was produced for the Cattlemen's Beef Board and state councils by National Cattlemen's Beef Association. We gratefully acknowledge Safe Foods Corporation for generously supplying cetylpyridinium chloride for these studies. We thank the participating processing plant and its personnel for cooperation. We thank Frank Reno and Gregory Smith for technical support and Carol Grummert for secretarial assistance.

\section{REFERENCES}

1. Anonymous. 1997. Official United States standards for grades of carcass beef. AMS-USDA, Washington, D.C.

2. Bacon, R. T., K. E. Belk, J. N. Sofos, R. P. Clayton, J. O. Reagan, and G. C. Smith. 2000. Microbial populations on animal hides and beef carcasses at different stages of slaughter in plants employing multiple-sequential interventions for decontamination. J. Food Prot. 63:1080-1086.

3. Barkocy-Gallagher, G. A., T. M. Arthur, M. Rivera-Betancourt, X. Nou, S. D. Shackelford, T. L. Wheeler, and M. Koohmaraie. 2003. Seasonal prevalence of Shiga toxin-producing Escherichia coli, including O157:H7 and non-O157 serotypes, and Salmonella in commercial beef processing plants. J. Food Prot. 66:1978-1986.

4. Barkocy-Gallagher, G. A., T. M. Arthur, G. R. Siragusa, J. E. Keen, R. O. Elder, W. W. Laegreid, and M. Koohmaraie. 2001. Genotypic analyses of Escherichia coli $\mathrm{O} 157: \mathrm{H} 7$ and $\mathrm{O} 157$ nonmotile isolates recovered from beef cattle and carcasses at processing plants in the Midwestern states of the United States. Appl. Environ. Microbiol. 67:3810-3818.

5. Barkocy-Gallagher, G. A., E. D. Berry, M. Rivera-Betancourt, T. M. Arthur, X. Nou, and M. Koohmaraie. 2002. Development of methods for the recovery of Escherichia coli O157:H7 and Salmonella from beef carcass sponge samples and bovine fecal and hide samples. $J$. Food Prot. 65:1527-1534.

6. Bosilevac, J. M., T. L. Wheeler, M. Rivera-Betancourt, X. Nou, T.
M. Arthur, S. D. Shackelford, M. P. Kent, D. Jaroni, M. Osborn, M. Rossman, J. O. Reagan, and M. Koohmaraie. 2004. Protocol for evaluating the efficacy of cetylpyridinium chloride as a beef hide intervention. J. Food Prot. 67:303-309.

7. Byrne, C. M., D. J. Bolton, J. J. Sheridan, D. A. McDowell, and I. S. Blair. 2000. The effects of preslaughter washing on the reduction of Escherichia coli $\mathrm{O} 157: \mathrm{H} 7$ transfer from cattle hides to carcasses during slaughter. Lett. Appl. Microbiol. 30:142-145.

8. Cutter, C. N., W. J. Dorsa, A. Handie, S. Rodriguez-Morales, X. Zhou, P. J. Breen, and C. M. Compadre. 2000. Antimicrobial activity of cetylpyridinium chloride washes against pathogenic bacteria on beef surfaces. J. Food Prot. 63:593-600.

9. Elder, R. O., J. E. Keen, G. R. Siragusa, G. A. Barkocy-Gallagher, M. Koohmaraie, and W. W. Laegreid. 2000. Correlation of enterohemorrhagic Escherichia coli $\mathrm{O} 157$ prevalence in feces, hides, and carcasses of beef cattle during processing. Proc. Natl. Acad. Sci. USA 97:2999-3003.

10. Galland, J. C. 1997. Risks and prevention of contamination of beef carcasses during the slaughter process in the United States of America. Rev. Sci. Tech. 16:395-404.

11. Kim, J. W., and M. F. Slavik. 1996. Cetylpyridinium chloride (CPC) treatment on poultry skin to reduce attached Salmonella. J. Food Prot. 59:322-326.

12. McDonnell, G., and A. D. Russell. 1999. Antiseptics and disinfectants: activity, action, and resistance. Clin. Microbiol. Rev. 12:147179.

13. Nou, X., M. Rivera-Betancourt, J. M. Bosilevac, T. L. Wheeler, S. D. Shackelford, B. L. Gwartney, J. O. Reagan, and M. Koohmaraie. 2003. Effect of chemical dehairing on the prevalence of Escherichia coli $\mathrm{O} 157: \mathrm{H} 7$ and the levels of aerobic bacteria and Enterobacteriaceae on carcasses in a commercial beef processing plant. J. Food Prot. 66:2005-2009.

14. Pitten, F. A., and A. Kramer. 2001. Efficacy of cetylpyridinium chloride used as oropharyngeal antiseptic. Arzneimittelforschung 51:588595.

15. Pohlman, F. W., M. R. Stivarius, K. S. McElyea, and A. L. Waldroup. 2002. Reduction of E. coli, Salmonella typhimurium, coliforms, aerobic bacteria, and improvement of ground beef color using trisodium phosphate or cetylpyridinium chloride before grinding. Meat Sci. 60: 349-356.

16. Sheridan, J. J. 1998. Sources of contamination during slaughter and measures for control. J. Food Safety 18:321-339.

17. Smith, D., M. Blackford, S. Younts, R. Moxley, J. Grey, L. Hungerford, T. Milton, and T. Klopfenstein. 2001. Ecological relationships between the prevalence of cattle shedding Escherichia coli O157:H7 and characteristics of the cattle or conditions of the feedlot pen. J. Food Prot. 64:1899-1903.

18. Xiong, H., Y. Li, M. F. Slavik, and J. T. Walker. 1998. Spraying chicken skin with selected chemicals to reduce attached Salmonella typhimurium. J. Food Prot. 61:272-275.

19. Yang, Z., Y. Li, and M. F. Slavik. 1998. Use of antimicrobial spray applied with an inside-outside bird washer to reduce bacterial contamination of prechilled chicken carcasses. J. Food Prot. 61:829832. 